\title{
correspondence
}

\section{Air quality by urban design}

To the Editor - Industrialization and rapid urbanization have led to high levels of air pollution in many of China's cities. This can significantly affect both physical and psychological health. Although emissions from industry, vehicles, cooking and heating are the main contributors to metropolitan pollution, the situation is compounded by poor city design ${ }^{1}$. Densely distributed, tall buildings can block and weaken winds and thus reduce the dispersion of pollutants. We argue for urban planning with careful consideration of building layout to improve pollutant dispersal ${ }^{1,2}$.

Fine particles in the atmosphere, particularly those smaller than 2.5 micrometres in diameter $\left(\mathrm{PM}_{2.5}\right)$, can have potentially significant impacts on climate change at regional levels ${ }^{3}$. The importance of these fine particles (of which black and organic carbon are essential subcomponents) in generating ambient air pollution has led to the inclusion of $\mathrm{PM}_{2.5}$ targets in China's National Ambient Air Quality Standard: maximum average concentrations of $35 \mu \mathrm{g} \mathrm{m} \mathrm{m}^{3}$ annually and $75 \mu \mathrm{g} \mathrm{m}{ }^{3}$ daily are to be enforced from $2016^{4}$. However, current $\mathrm{PM}_{2.5}$ concentrations are well above these limits in many Chinese cities $^{5}$. To meet the 2016 targets, all avenues for pollution reduction must be explored.

At the regional scale, industrial sources are the most significant contributor of $\mathrm{PM}_{2.5}$. Restriction of industrial aerosol emissions should help lower $\mathrm{PM}_{2.5}$ concentrations in cities. However, traffic and fuel burning for heating homes and cooking as part of people's daily routines are increasing. Such sources of fine particles are harder to monitor and restrict (Supplementary Information S1). Xi'an, the capital city of Shaanxi Province in western China, for example, has undergone massive urban development in the past 20 years. The population density in central Xi'an in 2010 was more than 11,270 people
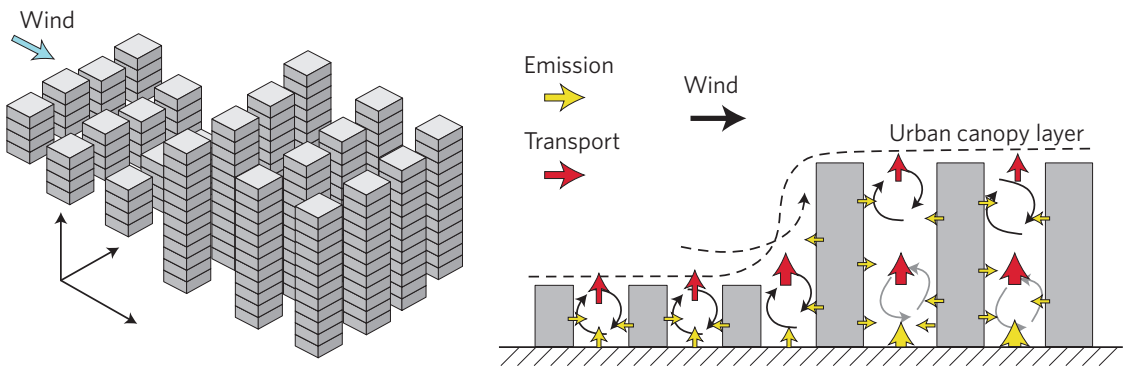

Figure 1 | Schematic illustration of air flow, pollutant concentration and dispersion with different building heights.

per $\mathrm{km}^{2}$, and the number of vehicles has increased by about 200,000 per year since 2009 (Supplementary Information S2). With continued extensive urbanization, it may become difficult to reduce $\mathrm{PM}_{2.5}$ concentrations in cities.

Some of the present urban $\mathrm{PM}_{2.5}$ issues in China may be attributable to the structure of the rapidly expanding cities. Here, building growth outpaces the expansion of the urban area ${ }^{1}$, and many cities grow upwards (Supplementary Fig. S2). A high density of tall buildings that obstruct wind flow in the canopy layer can lead to a rapid decline of wind speed, limiting the transport of pollutants out of the city ${ }^{6}$ (Fig. 1). In the long term, excessive concentrations of particulate matters could accumulate. Conversely, good air ventilation within the urban canopy layer would be conducive to pollutant dispersion and also help to retard the generation of secondary aerosols ${ }^{7}$ (Supplementary Information S3).

We suggest that urban development should consider carefully how the flow of air through a city can improve pollutant dispersion within the urban canopy layer ${ }^{1,2}$ (Supplementary Information S4). Reductions in the emissions of particulate matter may not be sufficient to improve urban air quality.
With high levels of activity in the Chinese construction sector, careful design of ongoing and future building projects could make a noticeable difference to urban ventilation.

References

1. Ren, C. \& Ng, Y. Y. Urban Climatic Map - An Information Tool for Sustainable Urban Planning (Building Industry Press, Beijing, 2011).

2. Gu, Z. L., Zhang, Y. W., Cheng, Y. \& Lee, S. C. Build. Environ. 46, 2657-2665 (2011)

3. Jacobson, M. Z. J. Geophys. Res. 107, D194410 (2002).

4. National Ambient Air Quality Standards. GB 3095-2012 (2012); http://kjs.mep.gov.cn

5. Ministry of Environmental Protection of the People's Republic of China. Report on air quality status in 74 cities of China in the first quarter of 2013 (19 April 2013); http://www.zhb.gov.cn

6. Kastner-Klein, P. \& Rotach, M. W. Bound.-Layer Meteor. 111, 55-84 (2004).

7. Huang, Y. et al. J. Hazard. Mater. 192, 1787-1794 (2011).

\section{Acknowledgements}

The authors appreciate helpful discussions with Dian Zhou and Yang Chen, and language editing by Chuck Yu. The study is supported by Project No. 2013FY112500, founded by the Ministry of Science and Technology of China.

Yunwei Zhang and Zhaolin Gu

Yunwei Zhang and Zhaolin Gu are in the School of Human Settlements and Civil Engineering, Xi'an Jiaotong University, Xi'an 710049, China. e-mail: guzhaoln@mail.xjtu.edu.cn 